\title{
Merging insight from solute fluxes and groundwater modeling in a semi-arid montane catchment
}

\author{
SUZANNE P ANDERSON ${ }^{1}$, LAUREN SALBERG ${ }^{2}$ AND \\ SHEMIN GE ${ }^{2}$ \\ ${ }^{1}$ University of Colorado Boulder \\ ${ }^{2}$ University of Colorado \\ Presenting Author: Suzanne.Anderson@colorado.edu
}

Channel heads mark the uppermost point of groundwater emergence at the surface within a catchment. Changes in stream chemistry with increasing distance downstream from the channel head should reflect differences in groundwater flow paths that reach the stream, and the chemical evolution of water along those flow paths. Here we examine groundwater and stream water chemistry at several points within Gordon Gulch, a $2.5 \mathrm{~km}^{2}$ headwater catchment in Precambrian gneiss bedrock in the Colorado Front Range, USA. Solutes derived from bedrock weathering (e.g., $\mathrm{Ca}^{2+}$ ) increase in concentration with distance downstream, consistent with emergence of longer, and probably deeper groundwater flow paths downstream. However, conservative solutes from atmospheric (rain or dust) sources (e.g., $\mathrm{Cl}^{-}$) do not change with distance downstream, consistent with passive transfer through the subsurface. These solutes show differing temporal trends that presumably arise from differing water residence times, reaction kinetics, and reservoir sizes. Chloride, for instance, appears to be evapo-concentrated both within the canopy and perhaps in the shallow subsurface, forming a limited reservoir of high concentrations that are "flushed" from the system during wetting events. It is clear from the geochemical, hydrological and groundwater modeling that this small headwater catchment is a groundwater dominated flow system, and that evapotranspiration plays a significant role in the overall water balance. 